\title{
Recent Isolation and Identification of Sheep Pox Virus from Menofeia Province, Egypt \\ S.S.A.Sharawi ${ }^{1}$, E.M.El-Nahas ${ }^{1}$, N.M.A.Yousef ${ }^{2}$, E.E.Rashed ${ }^{2}$ \\ ${ }^{1}$ Virology Dept., Faculty of Veterinary Medicine, Benha Univ., Benha, Egypt \\ ${ }^{2}$ Animal Health Research Institute, Dokki, Giza 12618, Egypt \\ E-Mail: SS-Sharawi@yahoo.com
}

\begin{abstract}
Sheep pox (SP) is a serious skin disease of sheep. Accurate and rapid diagnosis of SP is very important to control the rapid spread of disease in Egypt. In this study seven skin scabs from infected sheep at different localities in Menofeia province, Egypt were used for isolation and identification of SP virus. A total of 200 serum samples were collected from non-vaccinated and vaccinated sheep to detect the neutralizing antibodies for SP virus by serum neutralization test (SNT). Isolation of SP virus was done by inoculation on chorioallantoic membrane (CAM) of specific pathogen free embryonated chicken eggs (SPF-ECEs). Identification of SP virus isolate was confirmed by immunoflourescence (IF) and polymerase chain reaction (PCR) targeting SP virus PRO30 gene. In conclusion, SP virus is still circulated in Egypt and a test for differentiation between infected and vaccinated sheep with SP virus is required.
\end{abstract}

Keywords: SP virus, sheep, CAM, IF, PCR.

\section{Introduction}

Sheep pox virus, an epitheliotropic DNA virus, is classified as a member of Capripox virus genus that represents one of eight genera within the chordopox virus subfamily of the Poxviridae. Genus Capripoxvirus is comprised of sheeppox virus, goatpox virus, and lumpy skin disease virus that cause disease in sheep, goats, or cattle, respectively. These

Viruses are responsible for some of the most economically significant diseases of domestic ruminants in Africa and Asia [1]

Spatially, outbreaks of sheep pox have been reported in various countries of the world from time to time viz. Nigeria, Kenya, Greece, Australia, Turkey, Bangladesh, India [2, 3]. In Egypt, outbreaks of SP virus have been occurred in Karada and Sakha farms at Kafr ElSheikh province then reported in Hawamdya region at Giza province

The virus can survive for many years in dried scabs at ambient temperatures. It remains viable in wool for 2 months and in premises for as long as 6 months [4]. Transmission of sheep pox is efficient and suspected to occur via aerosol and insect vector [5].

Serology is limited in its applications for SP virus diagnosis due to the often low antibody response following infection [6], and the difficulties encountered with conventional, tissue culture dependent techniques [7].

Laboratory confirmation of disease is therefore frequently confined to identification of capripox virus or antigen, either through virus isolation on tissue culture and confirmation by virus neutralization or immunofluorescence or by recognition of the virions by electron microscopy. Electron microscopy, though providing a swift result may not be generally available at all laboratories in endemic areas [8].
In this study, we detect the prevalence of SP virus antibodies in unvaccinated and vaccinated sheep sera using SNT beside a trial for virus isolation and identification with the genotyping PCR that differentiate between SP virus and GP virus from sheep in Menofeia province, Egypt

\section{Materials and methods}

\subsection{Serum samples}

A total of 200 sera were collected from nonvaccinated and vaccinated sheep at different localities in Menofeia Province, Egypt. Where 64 sera were from non-vaccinated sheep and 136 sera were from vaccinated sheep with live attenuated Romanian strain of SP virus. These sera were frozen at $-20^{\circ} \mathrm{C}$ until they were used in SNT for screening sera to the presence of SP virus antibodies.

\subsection{Skin scabs}

During the years 2014 and 2015, sheep from different localities in Menofeia Province, Egypt, were reported to have developed skin scabs. Most of sheep had severe symptoms where nodules and scabs confined to non-wooly areas of the skin like fatty tail, around the udder, in face and in the perineal region. These sheep were unvaccinated against SP virus. Seven Skin scabs were aseptically collected either on $50 \%$ glycerol saline or frozen until they were used in viral isolation.

\subsection{Serum neutralization test (SNT)}

Micro-serum neutralization test was carried out according to OIE (2004) using madin derby bovine kidney (MDBK) cell monolayers. Reference antigen and antisera against SP virus used in the SNT were supplied by Pox virus Department, VSVRI, Abbasia, Cairo, Egypt. 


\subsection{Virus isolation in CAM}

Skin scabs homogenate was prepared in phosphate buffered saline (PBS, PH 7.4) with 100 $\mathrm{U} / \mathrm{ml}$ penicillin and $100 \mathrm{mg} / \mathrm{ml}$ streptomycin. The homogenate was lysed by freezing and thawing three times, and the supernatant was purified by centrifugation at $6000 \mathrm{xg}$ for $5 \mathrm{~min}$ at $4^{\circ} \mathrm{C}$ and filtration through a $0.45 \mathrm{~mm}$ pore-size cellulose acetate filter. SPF-ECEs after 9 days of incubation were inoculated with $0.2 \mathrm{ml}$ of the supernatant, which was dropped onto through CAM [9]. The sample was grown at least three times in CAM to increase the titer of the virus. The eggs were daily examined till 5-7 days post-inoculation. The embryos that died within the first $24 \mathrm{~h}$ were classified as nonspecific deaths. Signs on CAM were recorded and subjected to SP virus identification.

\subsection{Immunofluorescence assay (IFA)}

CAM cells were tested by indirect immunofluorescence assay (IFA). SP virus infection was confirmed using the SP virus reference antisera (supplied by Department of Pox Virus Vaccine Research and Production, Veterinary Serum and Vaccine Research Institute, Abbasia, Cairo, Egypt) as the primary antibody and a FITC-labeled rabbit anti-sheep IgG . Cells were examined by fluorescent microscopy.

\subsection{DNA extraction and PCR}

DNA was extracted from CAM suspension by using the QIAamp DNA mini kit (Qiagen, USA) according to the manufacturer's instructions. The primers used were: \# SpGp RNA Pol F 5' TCTATGTCTTGATATGTGGTGGTAG - 3' (Forward), SpGp RNA Pol R 5' AGTGATTAGGTGGTGTATTATTTTCC -3 (Reverse). The reaction conditions were: $95^{\circ} \mathrm{C}$ for $5 \mathrm{~min}, 35$ cycles of $94{ }^{\circ} \mathrm{C}$ for $30 \mathrm{~s}, 55{ }^{\circ} \mathrm{C}$ for $30 \mathrm{~s}$ and $72{ }^{\circ} \mathrm{C}$ for $30 \mathrm{~s}$ and a final extension step of 72 ${ }^{\circ} \mathrm{C}$ for $10 \mathrm{~min}$.

The primers were specific for PRO30 gene and able to differentiate between SP virus and GP virus where the expected size of the PCR product was $151 \mathrm{bp}$ for SP virus and $172 \mathrm{bp}$ for GP virus.

\section{Results and discussion}

\subsection{Serum neutralization test (SNT)}

Neutralizing antibodies were elicited in unvaccinated and vaccinated sheep against SP virus. From 64 unvaccinated sheep sera, 39/40 $(60.9 \%)$ were positive by SNT while $108 / 136$ (79.4\%) from 136 vaccinated sheep sera were positive Table (1).

\subsection{Virus isolation}

From the seven prepared samples, four were induced characteristic signs on CAMs after three successive passages. The CAMs were grayish, thickened and hemorrhagic fig (1). The pock lesions were detected in two CAMs without lethality to the embryos on the $5^{\text {th }}$ day post inoculation.

\subsection{Immunofluorescence assay (IFA)}

Two of CAMs that infected by skin scab homogenate were tested positive by IFA. Specific intracytoplasmic yellowish green fluorescent granules emitted from the infected cells fig (2).

\subsection{PCR}

The primer targeted the PRO30 gene was succeeded to amplify the specific SP virus products (151bp) from the extracted DNA products of two infected CAM using PCR fig (3).

\subsection{Discussion}

SP virus has been grouped in Risk Group II viral agent by Centres for Disease Control (CDC) and Prevention, Atlanta. These economic impacts explain the severity of the disease, and early diagnosis of the disease is essential to prevent it by means of vaccination [3]. So in this study prevalence of SP virus antibodies in unvaccinated and vaccinated sheep sera beside a trial for virus isolation and identification were adapted.

Live attenuated SP virus and subunit formulations have been used experimentally and in enzootic and outbreak areas as vaccines against sheep pox, goat pox, and lumpy skin disease [10, 11]. In Egypt, sheep pox is endemic and control program based on vaccination by live attenuated Romanian SP virus strain that succeed to induce neutralizing antibodies in $79.4 \%$ of examined sera of vaccinated sheep and absence of these antibodies in other vaccinated sheep may be associated with either of vaccine failure or inactivation of the virus vaccine that results in short period of immune response [2]. The presence of SP virus antibodies circulated among $60.9 \%$ of examined unvaccinated sheep sera were related to the mode of virus transmission through aerosol and insect vector either the wild type virus or attenuated strains [5] as well as sheep pox, goat pox and LSD viruses are serologically identical, and sheep may carried antibodies against goat pox and LSD without clinical signs. So a new trend is required to differentiate vaccinated from infected sheep and the need to improve the vaccine.

Pox virus isolation is thought to be a gold standard apart from its time-consuming [12]. In this study, four skin scabs samples were induced characteristic signs on CAMs after three successive passages. The biological characteristics in two membranes were resembling that produced by ORF virus $[13,14]$ that were grayish, thickened and hemorrhagic membrane due to its limited multiplication on chick embryo [15]. The other two samples produced pock lesion that either 
characteristic for SP virus or GP virus [16]. Although an equally cross-species SGPV strains still expected; the virus strains from one species are of a similar pathogenicity for the other, and the same virus appears to occur in the field outbreaks in mixed flocks [17]

FAT has been widely accepted as one of the most important techniques in the study of Viruses. It is possible to detect SPV antigen in infected edema fluid, skin, LK and LT cells [18]. Identification of SP virus in the four CAMs by IFA, the virus antigen was detected in two membranes produced pock lesion as recorded previously.

The clinical similarity between sheep pox and goat pox, and the inability to differentiate the two viruses by serological assays have led to the suggestion that sheep pox and goat pox are part of a disease complex caused by a single viral species and that observable host range specificities are the result of regional virus adaptations to sheep or goat hosts [19]. Currently, differentiation of these pathogens using molecular methods such as PCR targeting RPO30 gene [20] is simple, cheap and quick to differentiate SP virus and GP virus.

RPO30 gene of SP virus has a 21-nucleotide deletion in the 5' end compared to GP virus. Primers used in this study bind and amplify the partial RPO30 gene including the 21 nucleotide deletion. As a result SP virus yields the product size (151bp) which is lesser than the GP virus product size (172 bp). This genotyping PCR was successfully used for identifying SP virus and GP virus in isolate resources.

Table (1) SPV neutralizing antibodies in unvaccinated and vaccinated sheep sera from Menofeia Province, Egypt

\begin{tabular}{llll}
\hline sheep & Total No. of sera & No. of Positive sera (\%) & No. of Negative (\%) \\
\hline Non vaccinated & 64 & $39(60.9 \%)$ & 27 \\
vaccinated & 136 & $108(79.4 \%)$ & 28 \\
\hline
\end{tabular}

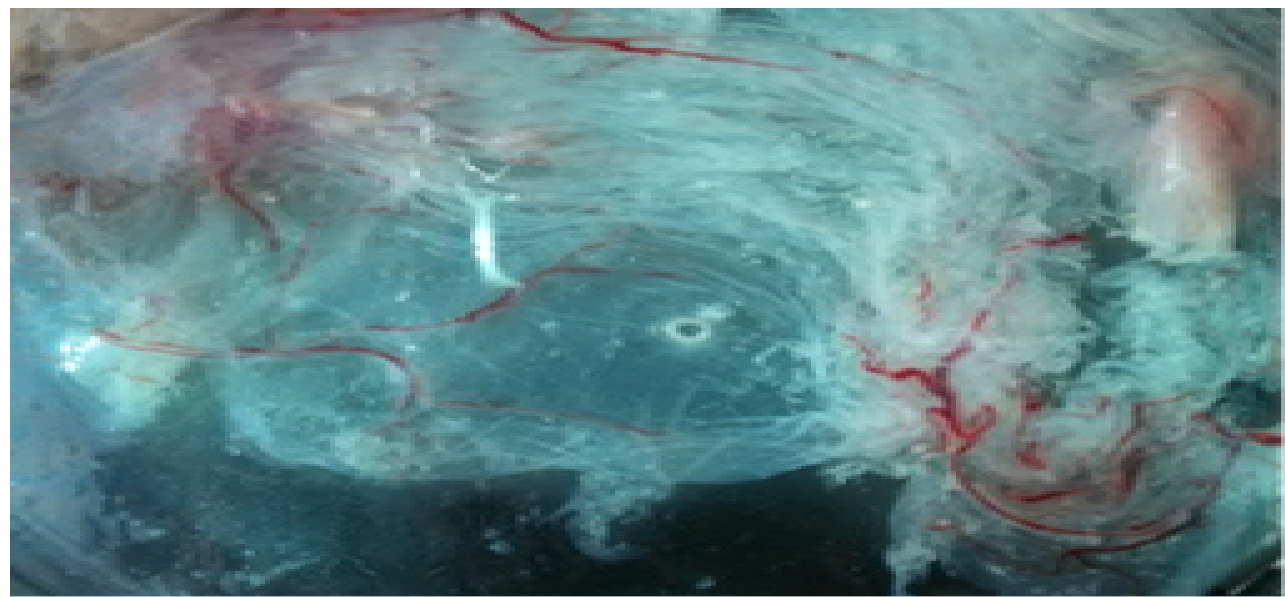

Fig (1) Inoculated CAMs with suspected SP virus samples were grayish, thickened and hemorrhagic

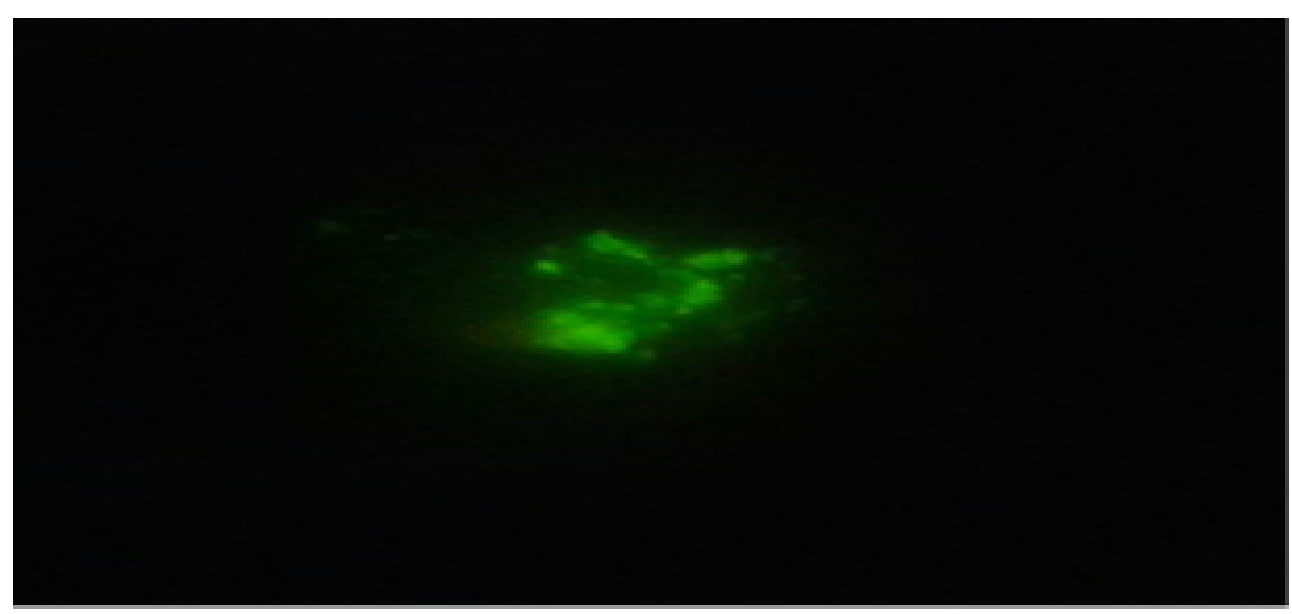

Fig (2) Specific fluorescent-reaction with rounded cells infiltrating in between and under the epithelial cells lining the CAM of cold freezed sections 


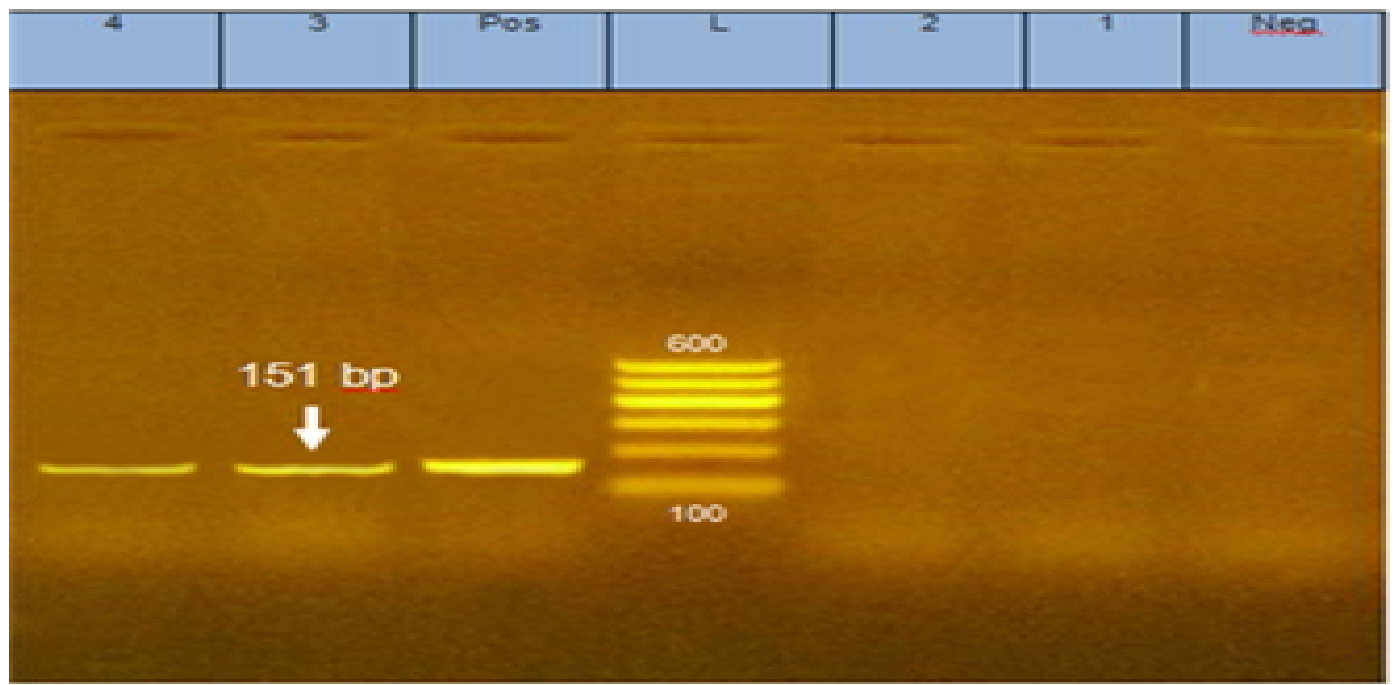

Fig (3) Specificity of the PCR to detect SP virus. Lane 1 (from right): negative control. Lanes 2, 3: -ve PCR isolate nol and 2. Lanes: 4: molecular weight marker (100 bp) Lane 5: +ve (151bp) control sheep Pox virus control. Lanes: 6-7: +ve PCR isolate no4 and 5

\section{Conclusion}

SP virus is still circulated in Egypt and a test for differentiation between infected and vaccinated sheep with SP virus is required.

\section{References}

[1] O.Mangana-Vougiouka, P.Martoulatos, G.Koptopoulos, K. Nomikou, N.Bakandritsos and O.Papadopoulos, 2000. Sheep poxvirus identification from clinical specimens by PCR, cell culture, immunofluorescence and agar gel immunoprecipitation assay. Molecular and Cellular Probes, vol.14(5), pp.305-310, 2000.

[2] V.M.Carn, Control of capripoxvirus infections. Vaccine vol.11, pp.1275-1279, 1993.

[3] V.Bhanuprakash, B.K.Indrani, M. Hosamani and R.K. Singh, The Current Status of sheep pox disease. Comparative Immunology Microbiology and Infectious diseases, vol.29, pp.27-60, 2006.

[4] Office International des Epizooties (OIE) Sheep pox and goat Pox. OIE Terrestrial Manual. Chapter 2.7.14, pp.1-12, 2010.

[5] J.J.Esposito and F.Fenner. Poxviruses, p. 28852921. In B. N.Fields, D. M. Knipe, P. M. Howley, R. M. Chanock, J. L. Melnick, T. P.Monathy, B. Roizman, and S. E. Straus (ed.), Fields virology, 4th ed. Lippincott, Williams and Wilkins, Philadelphia, Pa, 2001.

[6] R.P.Kitching, J.M.Hammond and W.P.Taylor. A single vaccine for the control of capripox infection in sheep and goats. Res. Vet. Sci. vol.42, pp.53-60, 1987.

[7] V.M.Carn, R.P.Kitching, J.M.Hammond and P.Chand, Use of a recombinant antigen in an indirect ELISA for detecting bovine antibody to capripox virus. Journal of Virological Methods, vol.49, pp.285-294, 1994.
[8] V.M.Carn, An antigenic trapping ELISA for the detection of capripox virus in tissue culture supernatant and biopsy samples. Journal of Virological Methods, vol.51, pp.95-102, 1995.

[9] T.V.Rao, and S.K.Bandyopadhyay. A comprehensive review of goat pox and sheep pox and their diagnosis. Anim. Health Res. Rev. vol.1,pp.127-136, 2000.

[10] R.P.Kitching and J.M.Hammond, Poxvirus, infection and immunity. In: ncyclopedia of Immunology Volume. 3 (Eds. Roith, I.M. and Delucs,P.J.) Academic Press, London. pp.1261-1264, 1991.

[11] C.K.Ngichabe, H.M.Wamwayi, T.Barrett, E.K.Ndungu, D.N.Black and C.J.Bostock. Trial of a capripoxvirus-rinderpest recombinant vaccine in African cattle. Epidemiol. Infect. Vol.118, pp.63-70, 1997.

[12] K.W.Chana, H.Wei-Li, W.Chi-Young, Y.Cheng-Hsiung, L.Fong-Yuan, C.Songkhla, and W.Min-Liang, Differential diagnosis of Orf viruses by a single-step PCR. J. Virol. Methods. Vol.160, pp.85-89, 2009.

[13] A.N.Sawhney, Studies on the virus of ecthyma contagiousum. I. Attempts at adaption or the virus to grow on chorioallantois of the growing chick embryo. Izv. Microbiol. Inst. Sofia.vol.18, pp.163-171, 1966.

[14] K.N.P.Rao, and M.Singh, Note on some observations on the cultivation of contagious pustular dermatitis virus on one-day-old eggs. Indian J. Anim. Sci. vol.51(3), pp.386-387, 1981.

[15]R.K.Joshi, S.Shakya, and S.L.Ali, (1996). Occurrence of Contagious pustular dermatitis among goats in Madhya Pradesh. Indian Vet. J. vol.73, pp.4-6, 1996. 
[16]S.Y.Al-Baroodi, Isolation and pathogenesis of sheep pox virus in Nineveh governorate. J. Vet. Sci. vol.23(1), pp.21-26, 2009.

[17]F.G.Davies, Sheep and goat Pox and lumpy skin disease. In: Gibbs EPJ, editor. Virus diseases of food animals, vol.2. London: Academic Press, 1981.

[18]J.P.Soman, Antigenic detection of sheep poxvirus in the sheep kidney and testes cell cultures by immunoflourescent test. Indian Veterinary Journal,vol.63(10), pp.793-795, 1986.
[19] F.G.Davies and C.Otema. Relationships of capripox viruses found in Kenya with two Middle Eastern strains and some orthopox viruses. Res.Vet. Sci. vol.31, pp.253-255, 1981.

[20] C.E.Lamien, C.Le Goff, R.Silber, Use of the Capripoxvirus homologue of Vaccinia virus 30 $\mathrm{kDa}$ RNA polymerase subunit (RPO30) gene as a novel diagnostic and genotyping target: development of a classical PCR method to differentiate Goat poxvirus from Sheep poxvirus. Vet. Microbiol. Vol.149, pp.30-39, 2011. 